\title{
Peer to Peer Energy Trading with Electric Vehicles
}

\author{
R. Alvaro Hermana \\ Jesús Fraile Ardanuy \\ Pedro J. Zufiria \\ Luk Knapen \\ Davy Janssens
}

\begin{abstract}
This paper presents a novel peer-to-peer energy trading system between two sets of electric vehicles, which significantly reduces the impact of the charging process on the power system during business hours. This trading system is also economically beneficial for all the users involved in the trading process. An activity-based model is used to predict the daily agenda and trips of a synthetic population for Flanders (Belgium). These drivers can be initially classified into three sets; after discarding the set of drivers who will be short of energy without charging chances due to their tight schedule, we focus on the two remaining relevant sets: those who complete all their daily trips with an excess of energy in their batteries and those who need to (and can) charge their vehicle during some daily stops within their scheduled trips. These last drivers have the chance to individually optimize their energy cost in the time-space dimensions, taking into account the grid electricity price and their mobility constraints. Then, collecting all the available offer/demand information among vehicles parked in the same area at the same time, an aggregator determines an optimal peer-topeer price per area and per time slot, allowing customers with excess of energy in their batteries to
\end{abstract}


share with benefits this good with other users who need to charge their vehicles during their daily trips. Results show that, when applying the proposed trading system, the energy cost paid by these drivers at a specific time slot and in a specific area can be reduced up to $71 \%$.

\section{Introduction}

M ore than $70 \%$ of European population is living in cities [1] . Most of this population is exposed to pollutants at levels above the limits declared safe by the World Health Organization (WHO) [2]. These pollutants do not only affect to the urban population, but also increase the global average surface temperature, warming the climate [3]-[5]. Governments are promoting different initiatives to reduce greenhouse gases (GHG) emissions, trying to mitigate the climate change effects and improve air quality in urban areas. In particular, the European Union (EU) has developed ambitious plans to reduce GHG emissions up to $85-90 \%$ by 2050 , through various initiatives [6]-[8].

Electrification of the road transportation represents an essential part of these plans, due to the fact that the transport sector is one of the largest GHG producers in Europe [8], [9]. In order to boost this deployment, EU Governments are promoting electric vehicles (EVs) through different initiatives [10]-[13]. As a direct result of these initiatives, EV registration has increased in Europe up to $49 \%$ in 2015 and Europe is leading the market share percentages for EVs, with significant differences depending on the country [14].

Despite the advantages of the electrification of the road transportation, a large scale deployment of EVs will impact on the distribution power grid, increasing power losses, voltage drops and unbalances, overloading distribution transformers and cables, generating harmonics and degrading power quality. This impact can also affect to a higher level of the power systems, increasing the investment in new generation units and transmission networks [15]-[19].

Traditionally, a way of reducing this impact is to develop smart charging algorithms for all EVs, filling the valleys of the electric demand profile, making a better use of baseload units and reducing both power losses and voltage deviation. One step ahead is to use EVs to support electric grid (known as vehicle to grid (V2G)) through an EV aggregator, as it was originally proposed in [20]. The energy stored in the EV batteries was initially used to reduce the peak power demands and since then, the feasibility of other electric markets has been analyzed in the literature [21].

P2P applications began to grow in the 90s, allowing millions of people around the world to share music, video and other digital contents over the Internet. After this first phase of sharing these type of intangible assets, these systems have evolved to create a sharing economy, interconnecting supply and demand in different markets, such as online auction, car-sharing, taxi cabs, parking lots, spare rooms, home services, etc. [22]. Recently, some new companies have broken the centralized infrastructure of the electric grid, allowing the direct connection of power producers and consumers, bypassing the central agent and trying to change the landscape of the electric power sector [23]. These first $\mathrm{P} 2 \mathrm{P}$ energy applications are connecting small distributed renewable energy generators with consumers interested in buying cheaper and more renewable energy.

In [24] a novel peer-to-peer (P2P) energy trading system among electric vehicles was initially proposed, helping to reduce the demand over the electric grid during the peak tariff periods. This paper is a significantly extended and revised version of [24], with the following new contributions: a better description and justification of the validity of the activity-based model; a new consumption model developed for different EVs, adding variability in order to obtain more realistic behaviors; the consideration of the charging and discharging battery efficiencies, which adjusts downwards the expected benefit of the proposed energy trading system, and finally, the main difference arises from a deeper mathematical formulation of the P2P trading system, analyzing the existence and uniqueness of the optimal solution.

In Section I, an activity based mobility model for the Flanders region (Belgium) is described. From this information, and assuming that all vehicles have been completely recharged during the off-peak night period, in Section II, a consumption model for each vehicle is presented and the driver agents of the mobility model are classified into three different sets: those who complete all their daily trips with an energy excess in their batteries (set A), those who need to and can charge their vehicle during their daily stops to reach their final destination (Set B) and a third type of drivers who can never use EVs in their daily trips without modifying their scheduled mobility behavior (set C). In this work it is assumed that only the two first sets of agents will make the transition from an internal combustion engine (ICE) vehicle to EV as a first approximation. Agents that must substantially change their mobility behavior (set $\mathrm{C}$ ) will not change their conventional vehicles until the EVs have a greater autonomy. The $\mathrm{P} 2 \mathrm{P}$ trading system is designed in two independent steps. Firstly, an optimization algorithm for each driver from set B is presented in Section III. This algorithm minimizes the electricity cost to be paid by each driver in the time and space dimensions, determining when and where these EVs will be charged during the business hours at a minimum cost, respecting the mobility restrictions. Secondly, taking advantage of the fact that EVs from sets $A$ and $B$ are parked in the same zone at the same time slot during the day, a P2P energy 
trading system among the two sets of EVs is proposed in Section IV. The results of this $\mathrm{P} 2 \mathrm{P}$ energy system are described in Section $\mathrm{V}$ and the final section presents the main conclusions.

\section{The purpose of activity-based modeling is to predict the travel behavior for each synthetic individual.}

\section{Activity Based Model}

Activity-based models predict the daily agenda for each member in a synthetic population. This section explains the concepts of the FEATHERS (Forecasting Evolutionary Activity Travel of Households and their Environmental Repercussions) model for Flanders (Belgium) [25] aimed to predict travel demand, and used as an input in the $\mathrm{P} 2 \mathrm{P}$ energy trading research described in this paper. This model was employed in [26] to predict the time dependent electric power demand for Flanders under specific assumptions of electric vehicle (EV) market share and several scenarios for vehicle charging behavior.

Daily agendas consist of a sequence of episodes each of which contains exactly one trip followed by an activity.

Activity locations are traffic analysis zones (TAZ) with an average area of $5 \mathrm{~km}^{2}$. For each activity the type (home, work, leisure, social visit...) as well as start ( $\left.t_{0}\right)$ and end $\left(t_{1}\right)$ times are specified. For each trip the transportation mode (car, walk, bike, bus, train...) is specified; trip timing follows from the activity timing.

In order to limit computational complexity, the FEATHERS model considers individuals to be mutually independent except for members of the same household. Effects of coordination constraints are reflected in the input data and hence captured by the data mining techniques used in FEATHERS.

The purpose of activity-based modeling is to predict the travel behavior for each synthetic individual as a function of several parameters. The FEATHERS model predicts the outcome of the decisions taken by each individual while building a daily agenda. The model covers both the activity planning and the scheduling stages. Planning involves decisions about the composition of the set of activities to be completed during a given day (what to do). Scheduling determines the sequence order and timing for the selected activities (when to do). Activities are either mandatory (work, school, pick/drop) or discretionary (leisure, shop, etc.).

The behavioral model consists of several sub-models: the most important and sophisticated ones are the location choice, the transport mode choice and the activity sequence choice models. Such models in turn make use of more basic components like gravity models for distance selection.

The agenda for each individual is generated by a series of mutually dependent decisions taken in a predefined order. Those decisions are data driven: their outcome is determined by a stochastic process making use of decision trees trained by means of survey data. Fig. 1 shows the main data flows involved in schedule prediction. The most important data sets are:

1) land-use data listing TAZ properties: number of inhabitants, number and size of schools, job opportunities, shops ...).

2) the synthetic population which is generated from census data such that the marginal distributions for specific quantities in each TAZ are similar for real and synthetic populations.

3) the performance characteristics of the transportation networks for each travel mode (car, train, bus, bike ...) expressed as expected travel times (impedance) between TAZ centroids for both peak and off-peak cases.

4) a set of decision trees trained on OVG survey data collected by periodic travel surveys in Flanders [27]. The 4th OVG survey campaign covers the period 2008-2013 and involves approximately 8000 respondents. Each decision tree relates the outcome of a specific decision to socioeconomic data and to the partial agenda already built (hence the mutual dependency of decisions).

Activity-based models are stochastic micro-simulators (Monte Carlo simulators), whose predictions are validated by comparing data aggregated at a specific level

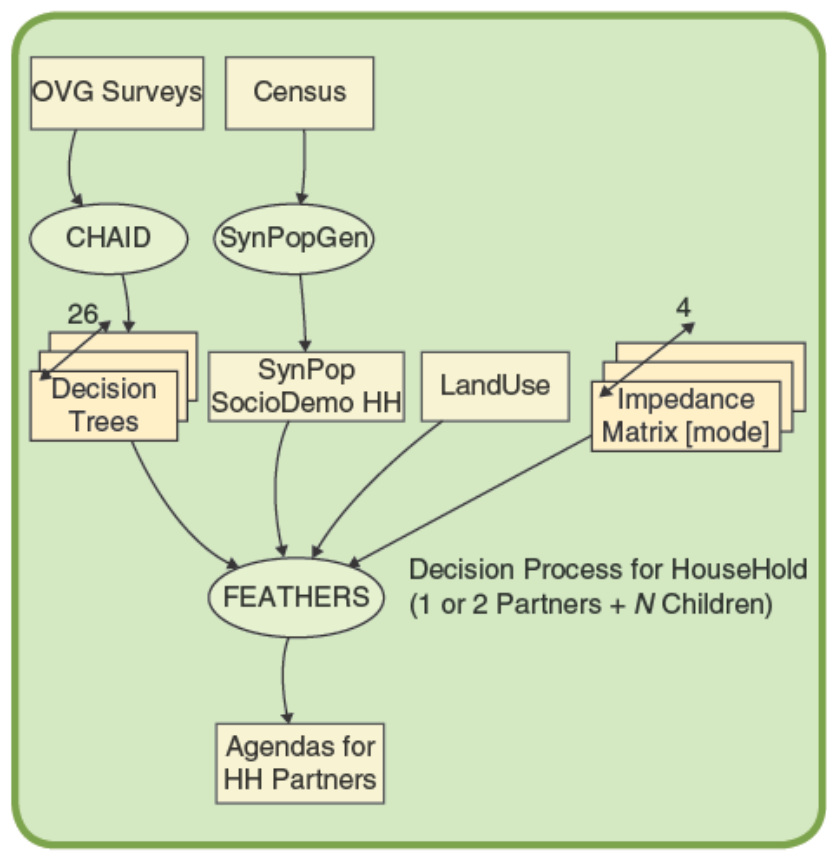

FIG 1 Data flows for the FEATHERS activity-based model. Ovals represent processes, rectangles represent data sets. 


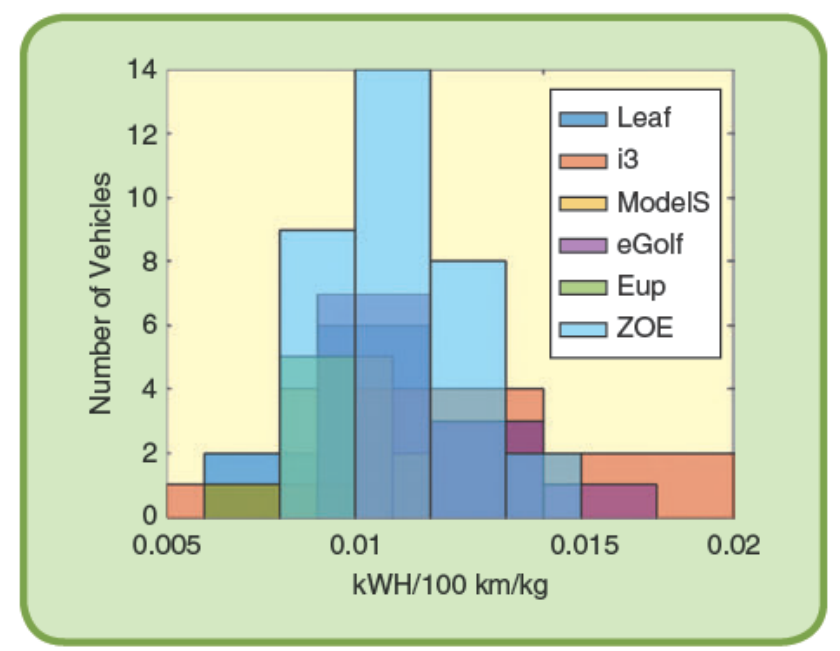

FIG 2 Normalized electric consumption for different models of EVs

to observations. FEATHERS was validated by aggregating traffic flows between TAZ for each hour of the day and loading the resulting demand onto the transportation networks. The resulting link flows for arterial network links, were compared to time dependent hourly flows derived from traffic counts. Commuting trips were validated by comparing the predicted arrivals for commuting trips to census data that apply to the complete population and specify the work zone for each individual [28].

Once all agendas have been predicted, they serve two purposes, using different techniques. The first technique aggregates detailed data in several ways to produce statistics applying to specific segments of the population (e.g. the number of trips with shopping purposes for a given segment of the population during a given period of the day). The second technique uses details from each predicted schedule to feed a specific model involving a single individual and aggregates this model's results [e.g. counting the number of commuting trips that can be driven by battery-only EV for people living in a particular TAZ and being able to charge at the work location (the specific model step); then deriving energy demand for each TAZ during working hours (the aggregation step)].

\section{Consumption Model and Drivers Classification}

\section{A. Consumption model}

There are different methods in the literature for estimating the average consumption $(\mathrm{kWh} / \mathrm{km})$ of EVs. The first type of methods estimates the energy consumption from a mathematical model which evaluates the power and energy requirements of an $\mathrm{EV}$ over a real trip defined by its GPS traces [29]. The second methodology estimates the consumption from recorded real consumption data using different regression techniques, determining the relationship between consumption and other input variables (distance, speed, acceleration, etc.) [30].

The only mobility output data provided by the FEATHERS model is the travelled distance. Therefore, it is not possible to use any of the previous methods proposed in the literature to estimate the vehicle consumption. In the original work [24], the energy consumption was assumed to be constant for all involved EVs (using a conservative value of $0.179 \mathrm{kWh} / \mathrm{km}$ ). In this work, a more realistic consumption model is derived, based on real data extracted from [31]. This data base contains more than 480,000 vehicles where car drivers have logged their own fuel (or electric) consumptions. We have focused on 6 different types of EVs, analyzing the real consumption from more than $120 \mathrm{EVs}$.

In order to provide variability to the consumption model and take into account different driver behaviors, each consumption sample for each vehicle type has been normalized by the vehicle's weight. The resulting consumption distribution is located between $0.005 \mathrm{kWh} / 100 \mathrm{~km} / \mathrm{kg}$ and $0.02 \mathrm{kWh} / 100 \mathrm{~km} / \mathrm{kg}$, with an average value of $0.011 \mathrm{kWh} /$ $100 \mathrm{~km} / \mathrm{kg}$ and with a slightly higher dispersion in case of the BMW i3 consumption, as it is shown in Fig. 2. This distribution is approximately fitted by a normal distribution. In order to generate different consumption profiles for different agents in the mobility model, initially, the weight of

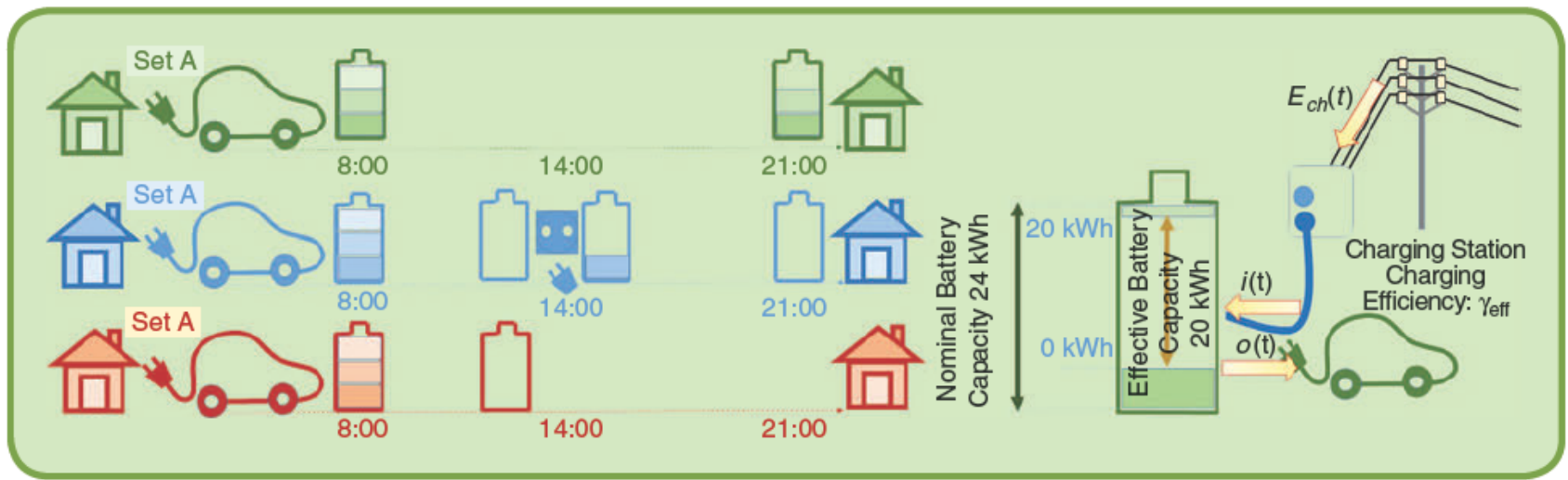

FIG 3 Classification of drivers depending on their daily trip distance. 
one of the six different EV models is randomly selected. Then, this value is multiplied by a randomly selected consumption sample extracted from the distribution, obtaining a particular electric consumption value to be used by a particular agent in the mobility model.

\section{B. Daily Trip Distance Evaluation}

According to the mobility model, there are 1,141,735 vehicles driving daily around the Flemish region.

It is assumed that only drivers that can fulfill their daily activities without any modification of their scheduled trips will make the transition from ICE vehicles to EVs. To evaluate the EV penetration rate in assumed conditions, all vehicles are fully charged at the beginning of the day, as a result of a charge during night off-peak hours. It is also assumed that the effective battery capacity of each EV is 20 $\mathrm{kWh}$, with a nominal capacity of $24 \mathrm{kWh}$ (see Fig. 3 right), therefore when the effective state of charge reaches $0 \%$, there are still $3 \mathrm{kWh}$ remaining in the battery. After evaluating the daily range for each vehicle in the model, taking into account their particular consumption, three different sets of drivers are found (Fig. 3 left):

Set A is composed by all drivers who can complete their daily activity schedule using their EVs without performing any intermediate charging along the day. These EVs will have an excess of $\mathrm{kWh}$ in their batteries at the end of the day. Set B consists of those drivers who can also complete their daily activities without modifying their mobility behavior, but their EVs will require intermediate charging along the day, taking the advantage that vehicles are parked during long periods of time. Finally, set $\mathrm{C}$ congregates those drivers who cannot complete their daily trips without modifying their daily mobility behavior. Drivers from this set will not initially adopt an EV and therefore, these drivers are not considered in this work.

Note that drivers from set B must charge their EVs during peak periods to complete all daily scheduled trips. Due to the high electricity prices at peak periods, vehicles from this set will be recharged only the bare minimum to reach their final destination, waiting for the off-peak night period to be fully recharged.

Fig. 4 shows the excess energy distribution stored in the battery packs of vehicles belonging to set $\mathrm{A}$ at the end of the day for the whole Flanders region. It is observed that most of these vehicles travel very short trips, consuming a small amount of energy (more than 200,000 vehicles store more than $18 \mathrm{kWh}$ ). The total stored energy amount is $13,246 \mathrm{MWh}$.

Fig. 5 presents the additional energy demanded by vehicles from set $B$ to reach their final destinations. It is ob- served that most of these vehicles require a small amount of energy (more than 30,000 vehicles will require less than $6 \mathrm{kWh}$ to finish their daily trips). The total demanded energy amount is $363.67 \mathrm{MWh}$, therefore, there is 36 times more energy stored in the batteries of vehicles from set $A$ than the total energy demanded by vehicles from set $B$.

\section{Intermediate Charging Process Optimization}

Drivers from set B have to recharge their EVs during their scheduled stops in business hours. Assuming that variable hourly grid electricity prices are known in advance (usually, in a day-ahead time horizon [32]) and taking into account their own daily scheduled activities, provided by the mobility model, car owners optimize their daily energy costs, scheduling where (in which TAZ) and when (at what time slot) they have to charge their vehicle at minimum

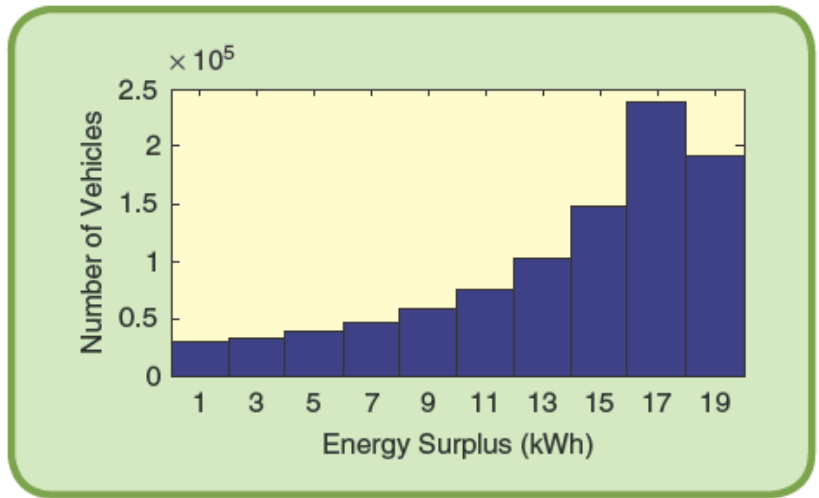

FIG 4 Total energy stored in batteries of set $A$ vehicles at the end of the day.

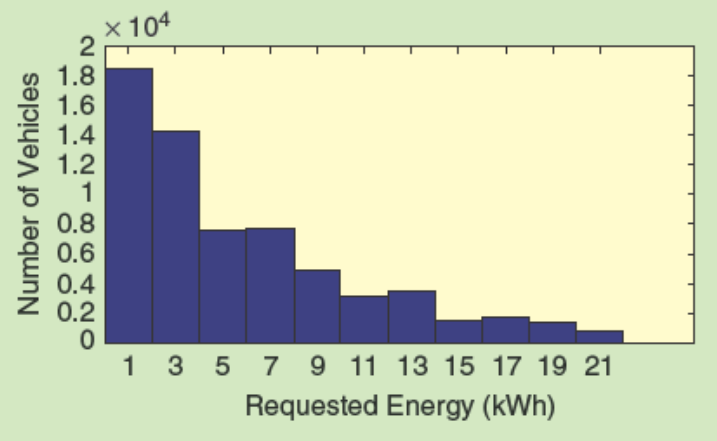

FIG 5 Total energy demanded by vehicles from set B to fulfil all scheduled daily trips. 
Table 1. Charging optimization problem constants.

$\begin{array}{lll}T_{\text {dep }}^{\text {arr }} & \text { Departure time } & \text { Arrival time } \\ S O C^{\text {max }} & \text { Maximum Effective State of Charge } & 20 \mathrm{kWh} \\ S O C^{\text {min }} & \text { Minimum Effective State of Charge } & 0 \mathrm{kWh} \\ \mathrm{CR} & \text { Charging energy limit } & 0.825 \mathrm{kWh} \\ \gamma_{\text {eff }} & \text { Charging efficiency rate } & 0.95\end{array}$

cost, without modifying their mobility behavior and fulfilling their daily agenda.

The objective function to be minimized for each agent belonging to set $B$ is given by

$$
\min _{i(t)}\left[\sum_{t=T^{\mathrm{dep}}}^{T^{\mathrm{er}}} E_{c h}(t) P_{r}(t)\right]
$$

where $P_{r}(t)$ is the grid electricity hourly price (in $€ / \mathrm{kWh}$ ), $E_{c h}(t)$ is the energy extracted from the electric grid to charge in the battery pack (in kWh) and $T^{\text {dep }}$ and $T^{\text {arr }}$ represent the departure time (when the first scheduled trip starts) and the arrival time (when the last scheduled trip finishes) respectively.

Note that $E_{c h}(t)$ depends on $i(t)$, which is the decision variable and represents the effective energy (in kWh) injected to the battery during the time slot $t$, as it will be shown in (5) and Fig. 3, through the battery charging efficiency.

This objective function is subject to the following restrictions:

$$
\begin{gathered}
S O C^{\min } \leq S O C(t) \leq S O C^{\max } \\
0 \leq i(t) \leq C R
\end{gathered}
$$

$$
\begin{aligned}
\operatorname{SOC}(t) & =S O C(t-1)+i(t)-o(t) \\
E_{c h}(t) & =V A(t) i(t) / \gamma_{\mathrm{eff}} \\
o(t) & =[1-V A(t)] \cdot \operatorname{con} . d(t) \\
\operatorname{SOC}\left(T^{\mathrm{dep}}\right) & =20 \mathrm{kWh}
\end{aligned}
$$

where (2) determines the limits for the effective battery state of charge (SOC) and (3) imposes the charging rate limit, with $C R$ representing the maximum energy transferred per time slot (in $\mathrm{kWh}$ ). The dynamic evolution of the battery state is given by (4). The current $S O C$ is equal to the previous $S O C$ plus the energy injected to the battery during the charging process, $i(t)$, minus the energy consumption due to driving activity, $o(t)$ (in $\mathrm{kWh}$ ). The following equation determines the amount of energy extracted from the electric grid, $E_{c h}(t)$ which is finally paid by the owner. This variable depends on the vehicle charging availability provided by the mobility model, $V A(t)$, (where $V A(t)=1$ if the car is stopped at this time slot and can be charged, or $V A(t)=0$ if the car is moving), and $\gamma_{\text {eff }}<1$ is the charging efficiency rate [33]. In this work, the consumption due to driving activity, $o(t)$ in (6), is proportional to the consumption rate derived by the consumption model, con (in $\mathrm{kWh} / \mathrm{km}$ ), and the total distance traveled, $d(t)$ which is also provided by the mobility model. Note that the consumption rate value con is different for each vehicle as it was previously described in Section III.

Finally, (7) is the initial condition of the effective $S O C$ and determines that all vehicles are fully charged just before departure. Equations (1-5) constitute a linear optimization problem that is solved using GAMS $^{\circledR}$ and CPLEX Solver optimizer for each of the EVs from set B.

Constants used for the optimization program are shown in Table 1. The day is divided in 96 time periods of 15 minute each, so the departure time refers to the period 00:00-00:15 and the arrival time to 23:45-24:00. The limits for the $S O C$ are set between 0 and $20 \mathrm{kWh}$, which is the effective battery capacity. The charging rate $C R$ is set to $0.825 \mathrm{kWh}$ for each period of 15 minutes, which is the maximum power delivered by a slow charging station of $3.3 \mathrm{~kW}$. Finally, the charging efficiency rate $\gamma_{\text {efr }}$ is derived from [34].

Fig. 6 shows the application of this optimal charging algorithm for a single EV belonging to set $\mathrm{B}$. The background colors indicate the particular zone where the car is parked when the agent is performing his/her activities. This user performs 3 daily trips: a first trip from 06:45 to 07:30,
FIG 6 Effective battery SOC evolution for a vehicle belonging to set B (blue line), grid electricity price (green line) and TAZ zones (background colors). 
leaving the blue TAZ and arriving to the red TAZ, traveling $12.73 \mathrm{~km}$. A second trip from 12:30 to $13: 45$, leaving the red TAZ and arriving to the grey one, travelling $59.48 \mathrm{~km}$ and the final trip, from 18:30 to 19:15, going back to the blue TAZ and traveling $44.85 \mathrm{~km}$. The total distance covered is 117.06 $\mathrm{km}$, which, given a consumption of $0.198 \mathrm{kWh} / \mathrm{km}$, implies a total consumption of $23.18 \mathrm{kWh}$. This value is above the effective battery capacity: therefore, this user needs to perform intermediate charging.

The scheduled charging is programmed in 2 periods: 07:30-08:00, just after arriving to the first destination, and 15:00-16:00, during its second scheduled stop. The effective SOC at the end of the day is 0 (that is, with $3 \mathrm{kWh}$ remaining in the battery), the minimum allowed, since ending the day with a small amount of energy would be inefficient: electricity cost is lower during the night than at any other period of the day.

As it was described above, the owners of these vehicles schedule their daily charging periods in advance, determining when and where they will recharge at minimum cost. Aggregating this information from all EVs from set B, the energy demanded in each TAZ and in each time period is evaluated.

Fig. 7 shows the temporal energy demand for a particular TAZ (\#904, the most demanded one) and the electricity grid price. It is observed that the maximum demand (1,382 MWh) is produced at $15: 00 \mathrm{~h}$, when the hourly electricity price is lowest during the central business hours. There are also some peaks, the first one at 8:00 $\mathrm{h}$ in the morning, as soon as the vehicles arrive at their first scheduled destination and the electricity price is still very low, and the second peak at noon, coinciding with a small reduction in the hourly electricity price.

Fig. 8 shows the spatial energy demand distribution per each TAZ at 15:00 h, coinciding with the lowest electricity price value during the business hours (highest energy demanded). It is observed that the demand is lower in the periphery, denoted by blue areas, and increases in larger

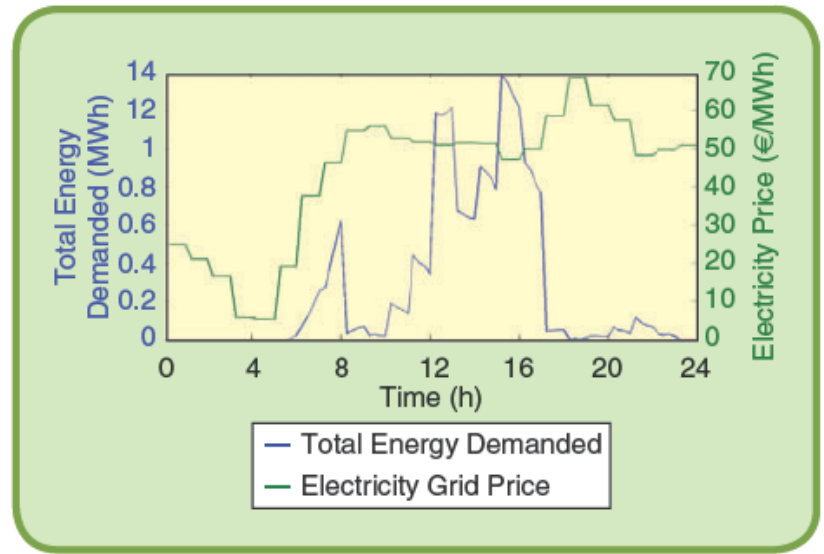

FIG 7 Temporal energy demand for TAZ \#904 (highest energy demand) and grid electricity price (green line).

urban centers such as Brussels, Gent, Brugge, Antwerpen and Hasselt.

\section{Peer to Peer Trading System}

In order to reduce the impact of recharging EVs on the electric grid during the business hours, a P2P trading system is proposed. In the same way as other $\mathrm{P} 2 \mathrm{P}$ shared economy business, the trading platform interconnects both market actors: electricity "producer" (vehicles with an excess of energy in their batteries-set A) and electricity "consumers" (vehicles demanding energy to finish their daily trips-set B).

The market mechanism operates as follows: at the beginning of the day, owners belonging to set B optimize their daily charging cost individually by programming when and where charge their vehicles, taking into account the day-ahead electricity price provided by the electric market operator [32] (May, 7th, 2014). This demanded energy can be provided directly from the electric grid at the

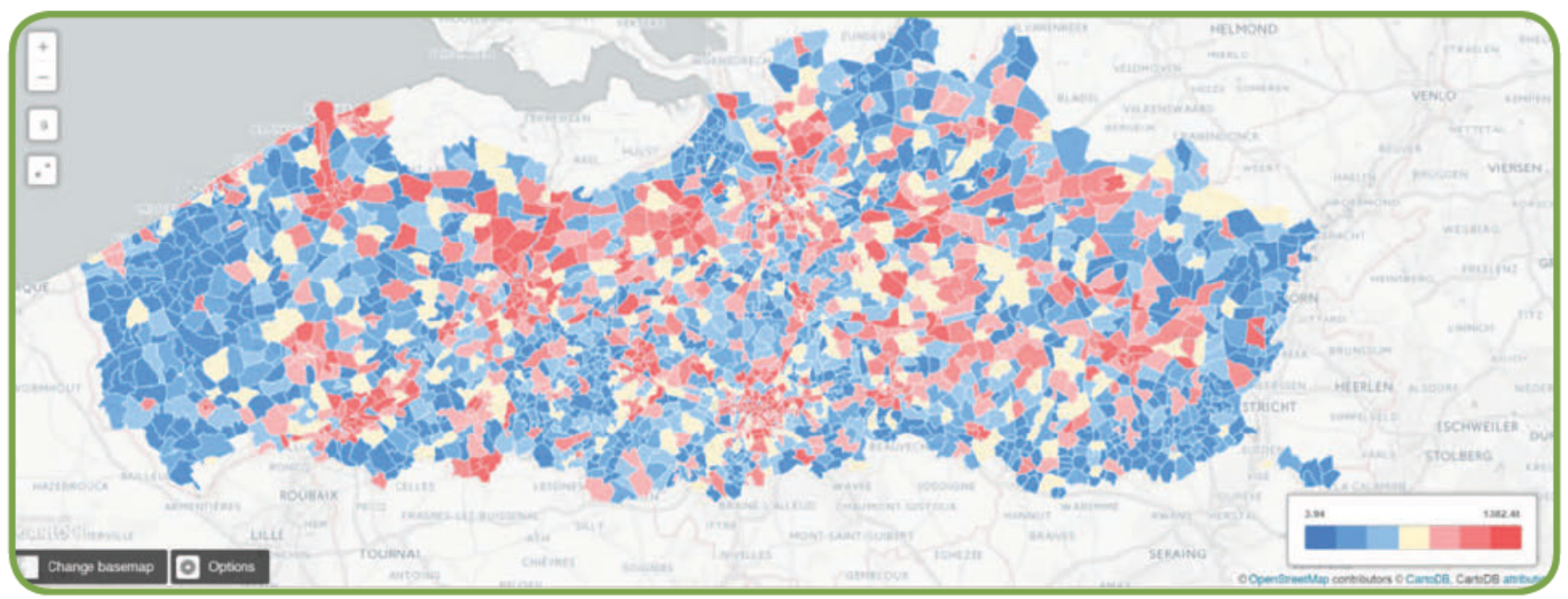

FIG 8 Spatial energy demand per each TAZ in Flanders region. Scale in kWh (more info available at: http://cdb.io/1BjL9pX). 


\section{In order to reduce the impact of recharging EVs on the electric grid during the business hours, a P2P trading system is proposed.}

price curve; $x_{i}^{o}$ indicates the energy available to exchange by the $i$ th EV (in kWh) with other vehicles, representing its offer, with $x_{i}^{o}>0, \forall i=1, \ldots, n$, and finally, $n$ represents the number of vehicles from set A parked at this time slot in a particular TAZ.

current grid tariff (which is different at each day-hour) or can be extracted from those vehicles belonging to set A that are parked at the same time period and the same TAZ. In this case, both actors should agree on a common electricity price.

Drivers belonging to set A are willing to sell energy if they are paid above the maximum value of the off-peak tariff plus an additional cost that takes into account the efficiency losses caused during the charging-recharging process and the battery degradation; this lower limit is denoted by $p^{\text {min }}$ and it is the same for all drivers. On the other hand, these drivers are willing to sell at the possible highest price with a fixed upper limit determined by the electric grid price at this particular time, $p^{\max }$. These drivers fix an amount of energy to share in this trading (named $x_{i}^{o}$ ), so that they have enough energy stored in their batteries to finish their daily trips plus an additional security margin to avoid problems in their daily trips.

Drivers belonging to set $\mathrm{B}$ are willing to pay as little as they can with an upper limit, determined by the electric grid tariff at this particular time, $p^{\max }$. If the $\mathrm{P} 2 \mathrm{P}$ trading price is higher than this value, these drivers will recharge their vehicles directly from the electricity grid. The total amount of energy demanded by all vehicles from set B in a particular TAZ at a particular time slot $t$, is denoted by $D$. This demand is inelastic because all vehicles belonging to this set must be charged in order to fulfill their daily trips; therefore, this demand will not depend on the final $\mathrm{P} 2 \mathrm{P}$ delivery price.

In order to determine a price to be paid in this $\mathrm{P} 2 \mathrm{P}$ trading system for each TAZ and for each time period, (denoted by $p_{i}$ ), an optimization algorithm is proposed. The objective function is to minimize the total cost of the energy exchange by all EVs at every TAZ and every time slot.

\section{A. Optimization of Price and Supply Distribution}

For each time slot, the offer price function of each $\mathrm{EV}$ from set $\mathrm{A}$ is given by

$$
p_{i}\left(x_{i}\right)=\alpha_{i} x_{i}+p^{\min }, \quad x_{i} \in\left[0, x_{i}^{o}\right], \quad i=1, \ldots, n
$$

where function $p_{i}$ represents the price paid to the $i$ th $\mathrm{EV}$ from set A (in $€$ ); $x_{i}$ denotes the energy extracted from this $i$ th $\mathrm{EV}$ (in $\mathrm{kWh}$ ); $p^{\text {max }}$ represents the maximum price to be paid to the $i$ th $\mathrm{EV}$ in $€$ and $p^{\text {min }}$ represents the minimum price to be paid to the $i$ th $\mathrm{EV}$ in $€\left(p^{\max }>p^{\min }\right)$; $\alpha_{i}=\left(p^{\max }-p^{\min }\right) / x_{i}^{o}$ denotes the slope of the TAZ's
Given the maximum energy deliverable by the charging point $E^{\max }>0$ in each time slot, we define:

$$
x_{i}^{\max }=\min \left\{x_{i}^{o}, E^{\max }\right\}, \quad \forall i=1, \ldots, n
$$

as the maximum practical energy deliverable by vehicle $i$, so that the total combined offer relies on the feasible compact region: $\Omega=\left[0, x_{1}^{\max }\right] \times\left[0, x_{2}^{\max }\right] \times \ldots \times\left[0, x_{n}^{\max }\right] \subset \Re^{n}$.

Finally, given $D>0$, the total energy demanded (in $\mathrm{kWh}$ ) by all EVs belonging to set B, parked in this particular TAZ during the considered time slot, we define the average cost function:

$$
f(\mathbf{x})=f\left(x_{1}, \ldots, x_{n}\right)=\frac{1}{D} \sum_{i} x_{i} P_{i}\left(x_{i}\right), \quad x \in \Omega
$$

so that the supply and demand equilibrium for each time slot solves the optimization problem:

$$
\min _{x \in \Omega} f(\mathbf{x}) \quad \text { subject to: } \sum_{i=1}^{n} x_{i}=D
$$

Let us call $\Omega_{1}$ the set of points of $\Omega$ satisfying (11); note that $\Omega_{1} \neq \varnothing$ if and only if:

$$
\sum_{i=1}^{n} x_{i}^{\max } \geq D
$$

\section{B. Quadratic Programming Formulation}

Problem (11) can be formulated as a quadratic programming one with cost function:

$$
\begin{aligned}
f(\mathbf{x}) & =\mathbf{x}^{T} \mathbf{Q} \mathbf{x}+\mathbf{c}^{T} \mathbf{x} \\
\mathbf{Q} & =\frac{1}{D} \operatorname{diag}\left(\alpha_{1}, \ldots, \alpha_{n}\right), \quad \mathbf{c}=\frac{p^{\min }}{D}(1, \ldots, 1)^{T}
\end{aligned}
$$

and the following linear restrictions $g_{j}(\mathbf{x}) \leq 0, j=1, \ldots, n$ and $h(\mathbf{x})=0$, where:

$$
g_{j}(x)=x_{j}-x_{j}^{\max }, j=1, \ldots, n ; h(\mathbf{x})=\sum_{i=1}^{n} x_{i}-D
$$

Note that a solution $\mathbf{x}^{*}$ of (11)-(13)-(14) will implicitly satisfy $\mathbf{x}^{*}>0$ (i.e., $x_{i}^{*}>0, \forall i$ ). The Karush-Kuhn-Tucker conditions to be satisfied by $\mathbf{x}^{*}$ are:

$$
\begin{aligned}
\left.\frac{\partial f}{\partial x_{i}}\right|_{x^{*}} & =\left.\sum_{j=1}^{n} \mu_{j} \frac{\partial g_{j}}{\partial x_{i}}\right|_{x^{*}}+\left.\lambda \frac{\partial h}{\partial x_{i}}\right|_{x^{*}}, \quad i=1, \ldots, n \\
\mu_{j} & \leq 0, \quad j=1, \ldots, n \\
\mu_{j} g_{j}\left(\mathbf{x}^{*}\right) & =0, \quad j=1, \ldots, n \\
h\left(\mathbf{x}^{*}\right) & =0
\end{aligned}
$$


which for (13)-(14) take the form:

$$
\begin{aligned}
\frac{2 \alpha_{i} x_{i}+p^{\min }}{D} & =\mu_{i}+\lambda, \quad i=1, \ldots, n \\
\mu_{j} & \leq 0, \quad j=1, \ldots, n \\
\mu_{j}\left(x_{j}-x_{j}^{\max }\right) & =0, \quad j=1, \ldots, n \\
\sum_{i=1}^{n} x_{i} & =D
\end{aligned}
$$

\section{Algorithm for Solving the System (16)-(19)}

Since $\mathbf{Q}$ is a (diagonal) positive definite matrix, the problem is computationally feasible; here we propose a simple algorithm for solving it.

1) Start by initially assuming that the minimum is reached in the interior of $\Omega$; then $\mu_{j}=0, j=1, \ldots, n$ and we get:

$$
x_{i}^{*}=D \frac{x_{k}^{o}}{\sum_{k=1}^{n} x_{k}^{o}}, \quad i=1, \ldots ., n
$$

2) If $x_{i}^{*} \leq x_{i}^{\max }, \forall i=1, \ldots, n$ then $\mathrm{x}^{*}$ is in $\Omega$ and solves the problem. If $x_{i}^{*}>x_{i}^{\max }$ for some $i$, go to the following step.

3) Let $J \subset\{1, \ldots, n\}$ be the subset of indexes for which $x_{j}^{*}>x_{j}^{\max }, \forall j \in J$. Then we redefine $x_{j}^{*}=x_{j}^{\max }$ (these component values remain fixed in the rest of the algorithm) and solve the system (16) and (19); then $\mu_{j}<0$, $j \in J$ and the remaining components $x_{i}^{*}, i \in\{1, \ldots, n\} \backslash J$.

4) If $x_{i}^{*} \leq x_{i}^{\max }, \forall i=\{1, \ldots, n\} \backslash J, \mathbf{x}^{*}$ solves the problem. Otherwise, add to the set of indexes $J$ those indexes for which $x_{j}^{*}>x_{j}^{\max }$, in this new stage; then go to the previous step to repeat the procedure.

The algorithm finishes after a maximum number of $n$ steps.

\section{Results}

In this section the different effects of the proposed peer to peer energy trading system are analyzed. First, the analysis focuses on the individual behavior of a vehicle from set $A$ and a vehicle from set $\mathrm{B}$. Then, TAZ areas are globally analyzed and they are categorized according to market behavior.

Fig. 9 shows the application of the $\mathrm{P} 2 \mathrm{P}$ trading system from the perspective of an EV belonging to set $\mathrm{A}$. This vehicle travels very short trips during the day, consuming just $c_{i}=2.95 \mathrm{kWh}$; therefore, considering the losses in battery discharge $\left(\gamma_{\mathrm{efr}}\right)$, its $x_{i}^{o}$ energy available for sharing in the trading process is: $x_{i}^{o}=\left(S O C^{\max }-c_{i}\right) \quad \gamma_{\mathrm{eff}}=$ $(20-1.95) .0 .95=16.19 \mathrm{kWh}$.

This vehicle is parked at its departure zone (blue background color) until 14:00, arriving at zone 2 (red) at 14:30. It stays there for 45 minutes, leaves at 15:15 and reaches zone 3 (grey) at 15:45, where it stays for 15 minutes. Then, the vehicle returns at the departure zone (blue), where it stays from 16:15 until the end of the day. The amount of energy left in its battery is $13.63 \mathrm{kWh}$, implying that the vehicle has sold a total of $2.61 \mathrm{kWh}$ in the P2P energy trading.

This P2P market for this particular EV starts at 06:00, when all vehicles have been charged during the night-time period and some of them have departed from home. During the first period in which the vehicle is parked (06:00-14:00), there are two periods of great energy exchange activity, from 06:00 to 08:00 and from 12:00 to $14: 00$, and it is reflected both in the P2P delivery price (black line in Fig. 9) and the decrease in the battery SOC. Those are the periods in which the grid electricity price is lower, and therefore most vehicles from set B had planned their charging. Once this vehicle reaches zone 2 (red), almost no energy is exchanged. Nevertheless, once the vehicle reaches zone 3 (narrow grey strip), it sells a large amount of energy during just 15 minutes $(0.37 \mathrm{kWh}$ from a maximum of 0.825 $\mathrm{kWh}$ for a 15 minutes period) at its maximum price during the day ( $33.24 € / \mathrm{MWh}$, while the grid price is $47.22 € / \mathrm{MWh}$ ); it can be inferred that the ratio between vehicles from set $A$ and those from set $B$ is rather low in this particular TAZ, but not low enough for the vehicle to sell its energy at grid price. The grid electricity price during that period (15:0016:00) is the smallest in the business hours (from 08:00 and 20:00); therefore most vehicles from set $B$ have scheduled their charging during such period, and this fact benefits the vehicle under study.

Finally, back at the departure zone (blue area), the vehicle sells a relatively large amount of energy between 15:15 and 16:00 $(0.5 \mathrm{kWh})$; after that, it barely sells any amount of energy until the end of the day $(0.15 \mathrm{kWh})$. The periods with lower demand are 18:00-19:00 and 23:00-24:00,

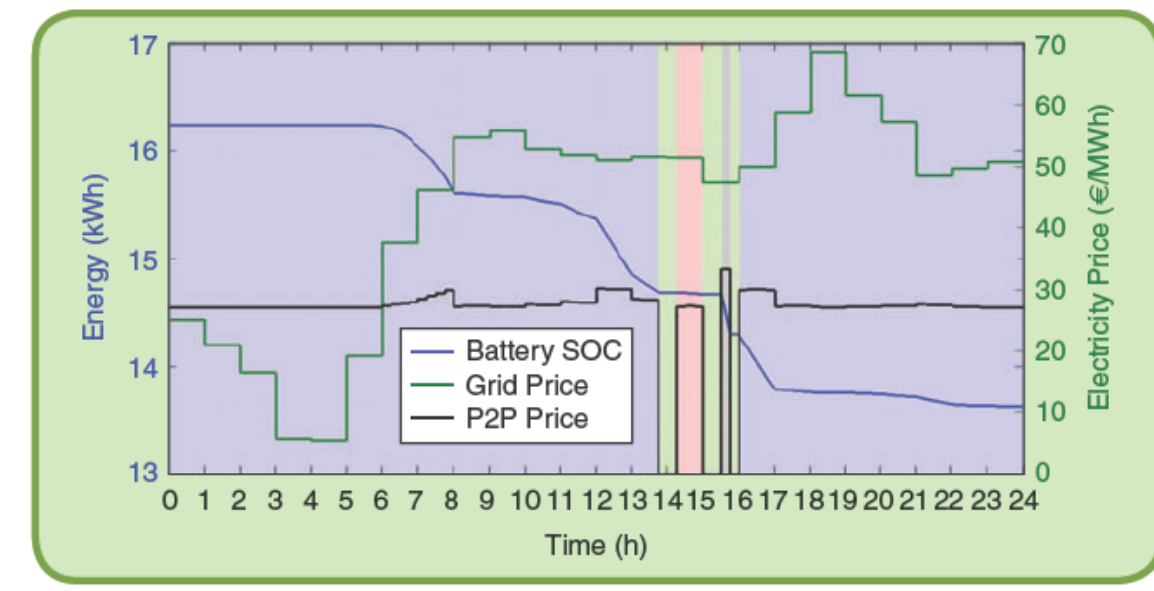

FIG 9 P2P trading behavior of a vehicle belonging to set A, representing the effective battery SOC (blue line), hourly grid electricity price (green line), P2P delivery price (black line) and visited TAZ during the daily trips (background colors). 


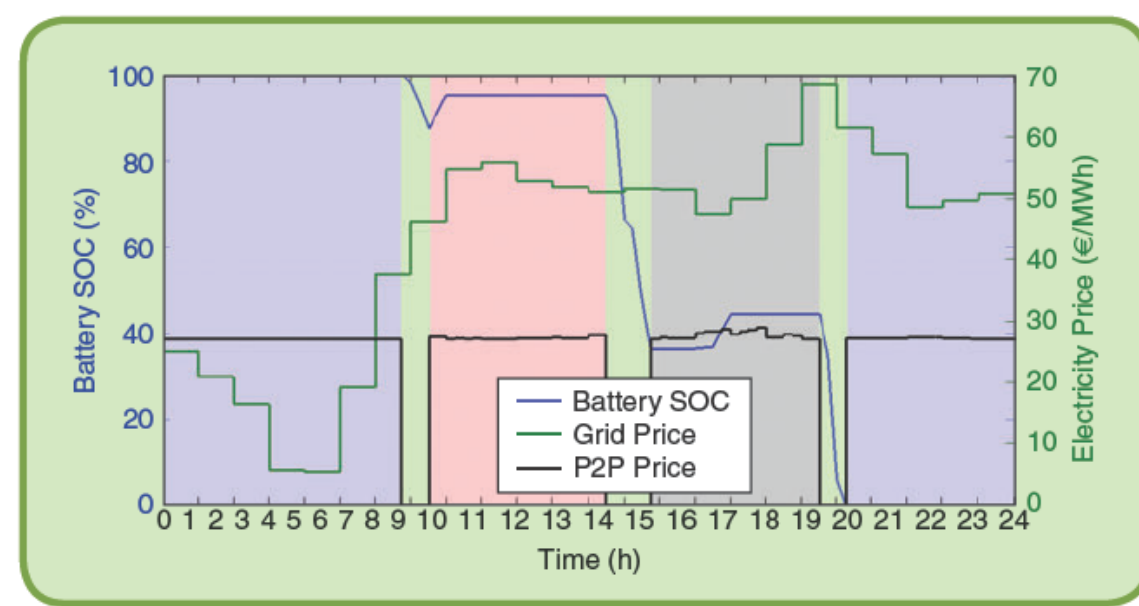

FIG 10 Effective battery SOC evolution for a vehicle belonging to set B (blue line), grid electricity price (green line), TAZ zones (background colors) and P2P delivery price (black line).

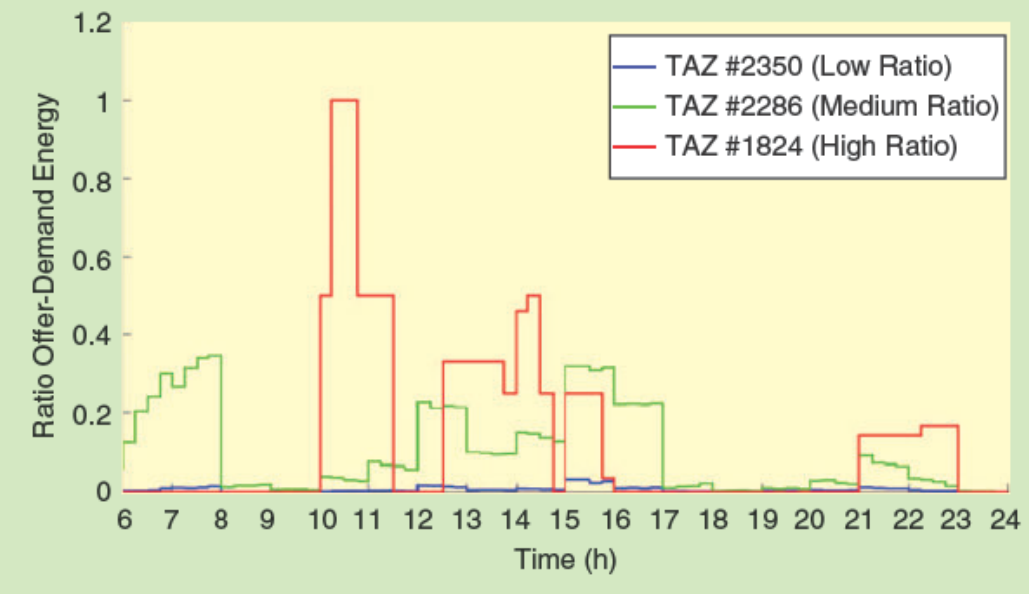

FIG 11 P2P ratio at three trading zones.

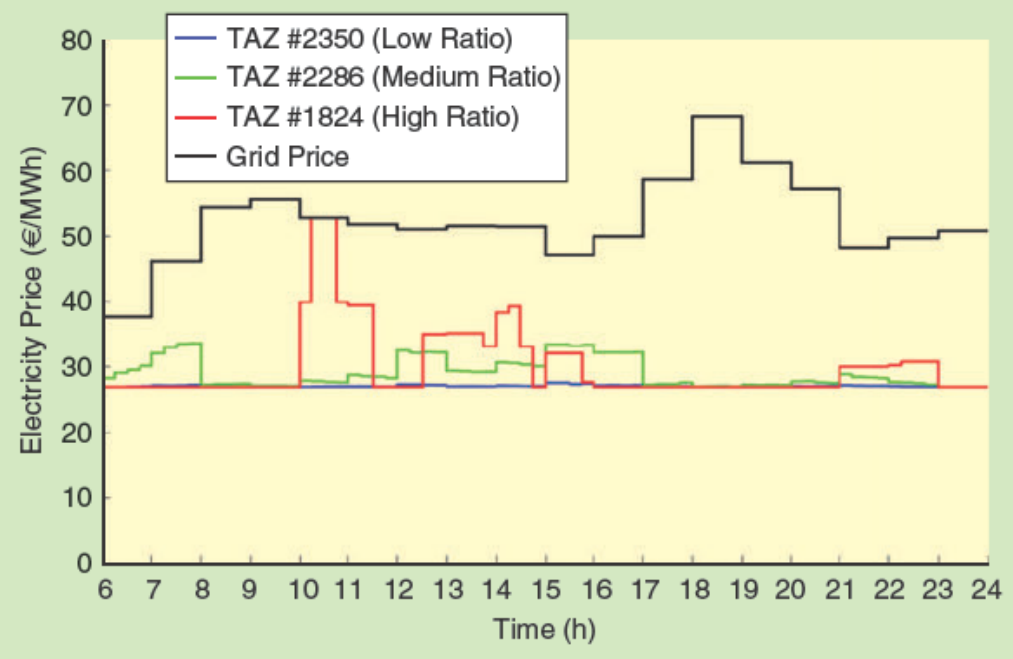

FIG 12 P2P delivery price at three zones and grid electricity price. which are, respectively, the highest grid price period and the last period of the day, when most of the vehicles have arrived at home.

The amount of energy left in its battery is $13.63 \mathrm{kWh}$, implying that the vehicle has sold a total of $2.61 \mathrm{kWh}$, for which it has required to charge $2.89 \mathrm{kWh}$ from the grid during the off-peak night period, taking into account the chargingdischarging efficiency. The total revenue from selling this energy is $0.077 €$ and the net benefit, if the energy has been charged at $16.5 €$ / MWh, is $0.029 €$. Daily vehicle consumption is $6.37 \mathrm{kWh}$, which implies a cost of $0.105 €$. In conclusion, the total cost of charging the vehicle has been reduced in $27.6 \%$.

Fig. 10 shows the day-charging for the EV from set B analyzed previously in Fig. 6. It can be seen that the cost of charging has been severely decreased, from $0.156 €$ to $0.0934 €$, which implies a reduction of $40.1 \%$ in the daycharging cost. Since fully charging the battery at night implies a cost of $0.3056 €$, the savings reach up to a $13.6 \%$ of the total daily cost.

Fig. 11 shows the ratio between the total number of vehicles demanding and total number of vehicles offering energy in three zones, whereas Fig. 12 shows the resulting $\mathrm{P} 2 \mathrm{P}$ delivery price in each zone. In TAZ \#2350 (blue line, very low ratio zone), there are many more EVs offering energy surplus than EVs demanding energy during the whole market period (an average value of 1043 vehicles from set $A$ and 91 vehicles from set $B$, representing an average ratio of 0.087 ). In TAZ \#2286 (green line, medium ratio zone) this ratio is slightly increased during certain periods, obtaining an average ratio of 0.346 . Finally, in TAZ \#1824 (red line, very high ratio zone) the number of vehicles is very low, with an average ratio of 0.4 , reaching near 1 at 10:30.

The interpretation for the low ratio zone is the following. The offered energy at each period varies between 
$752.4 \mathrm{kWh}$ to $990 \mathrm{kWh}$, while the maximum demanded energy during this period is $27.6 \mathrm{kWh}$. Therefore, the P2P delivery price barely varies between 27 )/MWh and 27.62 )/MWh. This price is reached at 15:00, when the grid electricity price is the lowest, although it is still $71 \%$ higher than the P2P delivery price (47.22 )/MWh).

The interpretation for the medium ratio zone is as follows: the offered energy at each period varies between $493 \mathrm{kWh}$ and $4291 \mathrm{kWh}$, while the maximum demanded energy is $1215 \mathrm{kWh}$. The maximum P2P delivery price is reached at $07: 45,32$ ) / MWh, while the grid price at this instant is 46.04 )/MWh (44\% higher). A similar price is reached during the periods $12: 00-13: 00$ and 15:00-17:00, whereas the demand is kept low during the other day periods (08:00-10:00 and 17:00-24:00).

Finally, the high ratio zone shows that both the offered and the demanded energy are low. The offered energy in each period varies between $0.825 \mathrm{kWh}$ (one vehicle) and $5.775 \mathrm{kWh}$ (seven vehicles) and the demanded energy varies between 0 and $1.65 \mathrm{kWh}$ (two vehicles). During the period 10:30-11:00 the offered energy is equal to the demanded energy, which implies that the $\mathrm{P} 2 \mathrm{P}$ delivery price is equal to the grid price, as it is shown in Fig.11. At other periods in which this ratio is still high (e.g., 11:00-11:45) the P2P delivery price is still lower than the grid electricity price but it is higher than the previous P2P delivery prices obtained in the other analyzed zones.

\section{Conclusions}

This paper has presented a novel P2P energ y trad ing system between EVs which can be used to reduce the impact of EV charging on the power grid during the pea $\mathrm{k}$ per iods.

The paper has analyzed the elect rification of a fleet of private vehicles in a nat ionwide scale, classi fying the drivers of EVs into different categor ies, depend ing on their daily inter med iate charge requ irements. It has been obser ved that the number of vehicles requiring inter med iate charge is much smal ler than those not requir ing it.

Two disjoint optimization problems are solved. Firstly, an individual optimal charging algorithm has been designed to obtain the best daily charging schedule (in time and space), according to public day-ahead grid electricity prices for those vehicles requiring intermediate charge. Once this individual optimization problem has been solved, the total expected demand, $D$, per each time slot and per TAZ is determined.

Secondly, a P2P energy trading mechanism between EVs which are parked in the same TAZ at the same time period is developed. This mechanism determines the optimal P2P delivery price to be paid at every location and during each time slot. The proposed P2P energy trading system severely modifies the price currently paid by those vehicles which require intermediate charge, reducing the total daily energy cost up to $71 \%$.

Decoupling both optimization procedures allows for a simple practical implementation where the decision of where and when to charge is independent of the consequent P2P saving benefits.

Future works will study the coupling between both optimization problems, analyzing how the first optimization procedures is affected if some $\mathrm{P} 2 \mathrm{P}$ market price information is available in advance; in addition we will also take into consideration other applicable business models which may maximize the monetary gain of the energy providers or may consider additional costs to the DSOs.

\section{Acknowledgment}

The research leading to these results has received funding from the European Union Seventh Framework Programme (FP7/2007-2013) under grant agreement $\mathrm{n}^{\circ} 270833$. 


\section{References}

[1] European Environment Agency. (2015) Urban Environment EEA-European Union [Online] Available: http://www eea europa eu /themes/urban

[2] European Environment Agency. "Air quality in Europe-2014 report," Publications Office of the European Union, Luxembourg, UK, EEA Report No 5/2014, 2014

[3] US Global Change Research Program. (2014) Climate change impacts in the United States National Climate Assessment DC [Online] Available: http://nca2014 globalchange gov

[4] National Science Foundation. (2015) Global climate change research explorer NSF, VA. [Online] Available: http://w w w exploratorium edu/climate/

[5] United Nations. (2015) Global issues on climate change United Nations, DC [Online] Available: http://w w w un org/en/globalissues/climatechange

[6] European Parliament and of the Council. (2015, May) Directive 2009/29/EC, Renewable energy sources, EU [Online] Available: http://ec europa eu/clima/policies/package/index_en htm

[7] European Commission. (2015, May) Climate action policies 2030 framework for climate and energy policies, EU [Online] Available: http://ec europa eu/clima/policies/2030/index_en htm

[8] European Commission. (2015, May) Climate action policies Roadmap for moving to a low-carbon economy in 2050, EU [Online] Avail- able: http://ec europa eu/clima/policies/roadmap/index_en htm

[9] Eurostat. (2015, Apr.) Transport energy consumption and emissions, EU [Online] Available: http://epp eurostat ec europa eu/statistics_explained/index php/Transport_energy_consumption_and_emissions

[10] Mayor of London. (2009, May) An electric vehicle delivery plan for London, UK [Online] Available: http://www london gov uk/sites/default/files/electric-vehicles-plan pdf

[11] Ea Energy Analyses. (2015, Jan ) Promotion of electric vehicles EU incentives \& measures seen in a Danish context Ea Energy Analy- ses, Denmark [Online] Available: http://w w w eaenergianalyse $\mathrm{dk} /$ reports/1276_promotion_electric_vehicles pdf [12] Ertrac. (2012, June) European Technology Platform on Smart Sys- tems Integration, Smart Grids European roadmap electrification of road transport (2nd ed) Ertrac, EU [Online] Available: http://www eg vi eu /uploads s Modu les / P ubl ic at ions/electrif ic at ion_road map_ web pdf

[13] Eurelectric. (2015, June) Map of electric vehicles projects in Europe, EU [Online] Available: http://w w w eurelectric org/ Maps/Interac- tiveMapEV/

[14] Avere France. (2016, Jan) Europe: Plus de 75000 véhicules élec- triques immatriculés en 2015 [Online] Available: http://w w w avere-

$6377 \&$ from espace adherent $=0$ france org/Site/Article/?article id=

[15] K Clement-Nyns, E Haesen, and J Driesen, "The impact of charg- ing plug-in hybrid electric vehicles on a residential distribution grid," IEEE Trans. Power Syst., vol 25, no 1, pp 371-380, 2010
[16] H Turker, S Bacha, D Chatroux, and A Hably, "Low-voltage transformer loss-of-life assessments for a high penetration of plug-in hybrid electric vehicles (PHEVs)," IEEE Trans. Power Del., vol 27, no 3, pp 1323-1331, 2012

[17] P T Staats, W M Grady, A. Arapostathis, and R S Thallam, "A statistical analysis of the effect of electric vehicle battery charging on distribution system harmonic voltages," IEEE Trans. Power Deliv., vol 13, no 2, pp 640-646, 1998

[18] P Richardson, D Flynn, and A. Keane, "Impact assessment of varying penetrations of electric vehicles on low voltage distribution systems," in Proc. IEEE Power and Energy Society General Meeting, 2010, pp 1-6

[19] F Geth, K. Willekens, K. Clement, J Driesen, and S De Breucker, "Impact-analysis of the charging of plug-in hybrid vehicles on the production park in Belgium," in Proc MELECON, 2010, pp 425-430

[20] W Kempton and S E Letendre, "Electric vehicles as a new power source for electric utilities," Transport. Res. D-TR E., vol 2, no 3, pp 157-175, Sept 1997

[21] W Kempton and J Tomić, "Vehicle-to-grid power fundamentals: Calculating capacity and net revenue” J. Power Sources, vol 144, no 1, pp 268-279, June 2005

[22] The Economist. (2013, Mar 9) The rise of sharing economy [Online] The Economist

[23] PeerEnergyCloud. [Online] Available: http://w w w peerenergycloud de

[24] R Alvaro, J Gonzalez, C Gamallo, J Fraile-Ardanuy, L Knapen, and D Janssens, "Vehicle to vehicle energy exchange in smart grid applications,” in Proc. Int. Conf. Connected Vehicles and Expo, 2014 pp 178-184

[25] T Bellemans, B Kochan, D Janssens, G Wets, T Arentze, and H Timmermans, "Implementation framework and development trajectory of FEATHERS activity-based simulation platform," Transp. Res. Rec. J. Transp. Res. Board, vol 2165, pp 111-119, 2010

[26] L Knapen, B Kochan, T Bellemans, D Janssens, and G Wets, "Using activity-based modeling to predict spatial and temporal electric vehicle power demand in flanders," Transp. Res. Rec , 2012

[27] OVG (Onderzoek Verplaatsingsgedrag Vlaanderen) sur vey results [Online] Available: http://mobielvlaanderen/ovg/ovg04 php

[28] B Kochan, T Bellemans, D Janssens, and G Wets, "Validation of an activity-based traffic demand model for flanders implemented in the FEATHERS simulation platform,” Comput. Intell. Traff ic Mobil., vol 8 , pp 80-105, Dec 2012

[29] T Jurik, A. Cela, R Hamouche, R Natowicz, A. Reama, S I Niculescu, and J Julien, "Energy optimal real-time navigation system," IEEE Intell. Transp. Syst. Mag, vol 6, no 3, pp 66-79, Fall 2014

[30] C Bingham, C Walsh, and S Carroll, "Impact of driving characteristics on electric vehicle energy consumption and range," IET Intell. Transp. Syst, vol 6, no 1, pp 29-35, Mar 2012

[31] MPG and Cost Calculator and Tracker. [Online] Available: http:// www spritmonitor de/en/

[32] Belgian Power Exchange. [Online] Available: http://www belpex be

[33] J Sears, D Roberts, and K Glitman, "A comparison of electric vehicle level 1 and level 2 charging efficiency," in Proc. IEEE Conf. Technologies for Sustainability, 2014, pp 255-258 